\title{
Factors Influencing Tourism-Horticulture Linkage among Smallholder Farmers in Zanzibar
}

\author{
Juma O. Abdalla \\ Department of Agricultural Extension and Farmers Training \\ Kizimbani Agricultural Training Institute \\ Tanzania \\ Kenneth M. K. Bengesi \\ Department of Policy Planning and Management \\ College of Social Sciences and Humanities \\ Sokoine University of Agriculture \\ Tanzania
}

\begin{abstract}
Despite the government support for inter-sectoral linkages between tourism and other economic sectors, there is inadequate information on the linkage between tourism and horticulture that employ large segment of population in Zanzibar. Failure to establish this linkage has undermined the potential contribution of tourism to the local economy that is driven by smallholder farmers mainly engaged in horticulture farming. Drawing from this background, this paper examined factors influencing tourism-horticulture linkage among smallholder farmers in Zanzibar. Findings revealed that factors influencing tourism-horticulture linkage are quality of horticultural products, hotels' tourist zones, nationality of hotel managers and consistency of vegetables and fruits supplied by farmers. Failure of farmers to take advantage of emerging opportunities in the tourist industry is partly due to inadequate enterprise mind-set among smallholder farmers. The paper recommends that strategic intervention is crucial to inculcate entrepreneurial mind-set among smallholder farmers to take advantage of emerging tourism market in Zanzibar.
\end{abstract}

Keywords: Tourism, horticulture, agriculture, fruits, vegetables, market linkage

\subsection{Introduction}

Tourism is the world's largest and one of the fastest growing industries (UNCTAD, 2007). Recently, the industry has become an important economic sector in developing countries including Tanzania (Honeck, 2008; UNCTAD, 2007). The tourism sector has continued recording strong growth in most countries, which are characterized by high levels of widespread poverty (UNCTAD, 2007). For tourism to contribute significantly to poverty reduction and overall economic growth, strengthening its linkage to other sectors especially agriculture becomes important. Building linkages between tourism and agricultural sectors is crucial to maximize economic impacts in developing countries (Rogerson, 2012). In line with this argument, Rueegg (2009) postulate that the tourism industry offers opportunities to stimulate local agricultural development through backward linkages that allow local farmers to supply food needs of tourism establishments such as hotels and lodges in their locality. Creating and strengthening linkages between the tourism and horticulture especially food sector can provide an adjacent market for locally produced horticultural food and beverage products (Bengesi and Abdalla, 2018; Boyne et al., 2001).

However, the linkage between tourism industry and local horticultural produce suppliers in Zanzibar is not clear despite the positive intentions of the government and other key stakeholders to promote tourism and horticultural sector (Bengesi \& Abdalla, 2018; RGZ, 2010). Farmers, particularly horticultural crops growers, are largely disconnected from the local tourism industry despite the fact that tourism consumes large proportion of fruits and vegetables as products of horticultural sector (RGZ, 2004). Continuous growth of tourism sector in Zanzibar recorded an increase of annual tourists visiting Zanzibar from 86, 918 in 1999 to 175, 067 in 2011 and registered 349 tourist hotels with about 7009 rooms and 13,198 beds. The increase in tourist visits signifies a need to increase the share of local horticultural products such as vegetables and fruits in local tourism market to cope with the growing tourist population (ZCT, 2011). 
The tourism accounts for over 51\% of the island's GDP and over $60 \%$ of all approved foreign direct investments in Zanzibar (Bengesi and Abdalla, 2018; MFEA, 2011) and contribute to local economy through provision of market for locally produced horticultural crops and products such as fruits, vegetables, milk, eggs and poultry meat (RGZ, 2004; RGZ, 2010). This suggests that tourism is one of the pillars of economy and improvement of livelihood in Zanzibar. In recognition of the importance of tourism sector in Zanzibar economy the government has launched several initiatives to create an enabling environment for sustainable tourism development. Among these initiatives include the adoption of the Zanzibar Strategy for Growth and Reduction of Poverty commonly known as MKUZA which advocates for inter-sectoral linkages (RGZ, 2010) and other government policies related to tourism development, such as the Zanzibar Tourism Master Plan (URT, 2003) and Zanzibar Tourism Policy Statement (RGZ, 2004). The initiatives carry the assumption that the economic benefits of the tourism sector will stimulate the development of other economic sectors such as horticulture through increased demand for local commodities (Anderson and Juma, 2011; Bengesi and Abdalla, 2018).

Despite these initiatives to support inter-sector linkages between tourism and other economic sectors, there is inadequate information showing how tourism and horticultural sub-sector linkage exists. In this view, this paper gives a thorough analysis of interface between tourism and horticultural sub-sectors and provides an important framework to explain linkages of tourism potentials in horticulture enterprise in Tanzania and Zanzibar in particular. This paper also presents factors influencing tourism-horticulture linkages in Zanzibar.

\subsection{Literature Review}

\subsection{General Overview of Agriculture in Zanzibar}

The agriculture sector in Zanzibar contributes an average of 30 percent of the total GDP (OCGS, 2013). This contribution to the GDP is attributed by its dominance in foreign exchange earnings, which currently accounts to over 70 percent. However, the country depends on limited agricultural commodities as primary export items confined to cloves and seaweed. Other potential export commodities include spices, marine products and fruits which have so far registered insignificant export proportion (ZATI, 2009). Agriculture employs about 60 percent of Zanzibar's labour force, and on average, 70 percent of the population depends directly or indirectly in the agriculture sector for their livelihood (OCGS, 2013).

Zanzibar's Agriculture sector is mainly dominated by small-scale subsistence farming, with low productivity of land, labour and other inputs (Bengesi \& Abdalla, 2018; RGZ, 2010). According to ZATI (2009), Zanzibar typically consumes more staple foods than it produces (banana, sweet potatoes, yams, maize), and for majority of these staples, Zanzibar has almost always been in deficits. This is caused mainly by limited capacity of institutions coordinating the sector; continued use of traditional technologies (non-mechanized tools, unimproved seeds and planting materials); inadequate agricultural services support (extension, research); lack of rural financing; marketing bottlenecks; declining soil fertility; overexploitation of natural resources; heavy reliance on rain-fed agriculture; and non-conducive land tenure systems. All these together have forced the majority of farmers to produce only for subsistence (RGZ, 2010).

\subsection{Tourism in Zanzibar}

Tourism is the fastest growing sub-sector within the services sector in Zanzibar's economy, and it is one of the most important sectors with great potentials for growth as identified being a source of Zanzibar's foreign currency earnings by 70 percent (Bengesi and Abdalla, 2018; MFEA, 2009). According to MFEA (2009), tourism currently represents about $51 \%$ of Zanzibar's GDP. Recent data by the Zanzibar Commission for Tourism showed tourism to increasingly becoming a leading economic sector in the island, providing 11,500 workers with direct employment and an additional 45,000 people engaged in tourist activities (RGZ, 2009). Zanzibar is looking at tourism as the leading foreign revenue source, as the number of foreign tourists visiting the island has been growing in the last two decades (MFEA, 2009). The number of tourists visiting the Isles has been growing at 9.6\% annually which is attributed to improved infrastructure including a modernized airport, roads and friendly environment (OCGS, 2013).

According to ZCT (2011), some of tourist attractions that potentially accelerate growth of tourism in Zanzibar are Stone Town with its wealth of historical buildings and traditional Swahili culture; marine environment in both Unguja and Pemba characterized by coral reefs suitable for snorkelling and diving; offshore islands and coral reefs (Changuu, Chumbe, Mnemba); big game fishing; 
Sea turtle and dolphins; sand beaches and extensive water areas used mostly for traditional fishing activities are particularly noteworthy. Other attractions include historical cultural sites, such as the ruins of Maruhubi Palace, the ruins of Mtoni Palace, the Kidichi and Kizimbani Persian Baths, and the Mangapwani Slave Cave. There are also Spice Tours, Jozani and Ngezi Forest Reserves (renowned for their diverse and rare botanical species and the presence of monkeys, fruit bats, antelopes, wild pigs, and a wild variety of birds). Arts and crafts, the Pemba essential oils factory and eco-tourism attractions complete the list. The foregoing endowments and others not mentioned here collectively confer comparative advantage in tourism on Zanzibar. The challenge confronting the industry is the ability to develop the requisite infrastructure and the capacity to provide services at the least cost, and thus gaining competitive advantage in the industry (OCGS, 2013).

While there is no current data directly linking the growth of tourist arrivals to Zanzibar's economic growth profile, one can clearly associate growth in some sub-sector activities with growth in tourism (MFEA, 2009). Some of these activities include hotels and restaurants, transport and communications, construction, manufacturing, including arts and crafts (production of wooden chests and doors, picture frames, brass, copperware and jewelry) as well as growth in agricultural production (e.g., staple foods, horticulture, spices, etc.). The evidence includes the 9 percent average annual growth in hotels and restaurants, the 17 percent average annual growth in transport and communication, the 18 percent average annual growth in construction, as well as the increased demand for agricultural products that has led to increased production in crops, livestock and fisheries (MFEA, 2009). Other indicators are growth in retail sales in response to the observed growth in tourist arrivals, although no such data are officially compiled for Zanzibar (OCGS, 2013). About 50 percent of the Isle's population is expected to be involved in tourism activities by the year 2020, forecasting a robust growth of the sector in few years to come. The tourism sector will be a major catalyst in the promotion of agriculture, employment, and fisheries and helping in creating more jobs in local industries (RGZ, 2004).

\subsubsection{Economic Benefit of Tourism Industry}

The tourism is linked to poverty reduction because of its contribution to the economic development of the destinations (Luvanga and Shitundu, 2003). Several reasons are advanced to why tourism is an effective tool for the economic growth. Tourists, as consumers arriving at the destination, provide local communities with the opportunities for producing and selling additional goods and services on exchange of cash (Honeck, 2008). This means tourism contribute to raise local production of additional goods and services such as agricultural products (i.e. fruits and vegetables) and the obvious outcomes from such activities are income and employment opportunities to the local communities.

Tourism can develop in poor and marginal areas with limited export and diversification options by attracting tourists due to their naturality, culture, wildlife and landscape value (Luvanga and Shitundu, 2003). This means tourism can create employment opportunities and income generating projects in poor and marginal areas in the same way it does in other areas. Viewing this way will imply that tourism is among few sectors that can benefits communities in diverse ecological regions. Given the fact that horticulture is among potential source of food supplies; sustaining the tourism sector is likely to stimulate growth of horticultural sector.

Tourism also offers labour-intensive and small-scale opportunities compared to other non-agricultural activities (UNCTAD, 2007). The sector employs high proportion of women, semi-skilled labour, and values natural resources and culture, which may feature among the few assets belonging to the poor (Luvanga and Shitundu, 2003). This means tourism, through employment creation and income generation, offers a relatively wider range of poverty reduction opportunities to many members of the society, including vulnerable groups such as women. Therefore, the analysis of interface between tourism and horticultural sub-sectors provides important framework linkages of tourism potentials in horticulture enterprise.

\subsubsection{Economic Benefit of Horticultural Enterprise}

Farmers engaged in horticultural crop production can earn higher net farm incomes than those growing staple crops (Bengesi, 2018; Bengesi and Abdalla, 2018). The study on value chain analysis on fruits and vegetables in Zanzibar conducted by the Volunteer Services Overseas (VSO, 2015) explained the profits accrued from horticultural crops, for instance, tomato and green pepper in Zanzibar to be five to eight times more than that of cereals. In addition to the economic benefits of horticulture for the producer, the high labour demands of horticultural production and related processing industries have the added benefit of local employment generation (Ali et al., 2002). 
A short growth cycle of vegetables and fruits gives an advantage over cereal crops, which have relative longer growth cycles. Shorter growth cycle allows horticultural crops to grow several cycles in a year calendar that leads to high profit in a very short period.

\subsection{Linkage between Tourism Sector and Local Agriculture}

Successful broadening and deepening of local linkages between tourism and horticulture is an important part of making tourism work for economic diversification (Rogerson, 2012). According to Rogerson (2012), without inter-sectorial collaboration and fomenting sustainable linkages between tourism demand and other sectors in the destination economy, tourism will fail to work as a trigger for local entrepreneurship. Therefore, for tourism to contribute to the local economy, improve rural livelihood and alleviate poverty, it has to develop linkages with different sectors such as agriculture which is an important economic source for the poor (Bengesi and Abdalla, 2018; Mshenga, 2010).

In developing countries, there are different reasons for smallholder farmers to supply food products to tourist hotels. Rogerson (2012) pointed out that, supplying formal tourism establishment with food products can build upon the existing skills of the poor without changing their livelihood strategies. In addition, the use of food products involves utilizing the productive assets of the poor in terms of land and labour. New skills learned in the production of food for tourism establishments also might allow smallholder farmers to transfer such skills to other local food producers in supply chains. Meyer (2007) cited by Rogerson (2012) asserted that, pro-poor tourism proponents also suggest an untapped potential exists for poor people to furnish genuine locally produced food for which there is a growing demand.

\subsubsection{Challenges of Linkages between Tourism Industry and Local Producers}

Although there is widespread agreement that increased demands of horticultural products from tourism should be met by local agricultural supplies as asserted by Ashley et al. (2006); Ruegg (2009); Mshenga and Owuor (2009) and Mshenga (2010), Timms with Neill (2011) and Rogerson (2012) found that, the empirical part of achieving these benefits, for the most part, have been less and less. Torres and Momsen (2011) identified various critical constraints preventing local producers' involvement in supply of food products to tourist establishments. Ashley et al. (2006), focusing on the local economy in the Caribbean, reported that among challenges observed as far as local sourcing is concerned are quality, quantity and regularity of supply are often inadequate; local producers are not sufficiently aware of hotel requirements and how to match tourist preferences to the required quality.

The challenges were further classified by Anderson and Juma (2011), and Rueegg (2009) into different categories namely demand-related, supply-related, marketing and intermediary, legal and institutional-related, as well as government policy factors/challenges. Demand-related challenges include factors such as type of accommodation with respect to ownership, size and class of accommodation, tourism industry maturity, health and safety concerns, training and nationality of chefs among others. Supply-related factors include physical proximity, quality and quantity of local products supplies, high prices of locally produced food and undercapitalization of the agrarian market. Examples of marketing and intermediary factors are marketing and infrastructure constraints, mistrust between the two parties, spatial patterns of supply and lack of information.

The government policy factors may include over-emphasis on tourism and neglect other sectors, unfavourable investment policy and lack of credit and micro finance support (Anderson and Juma, 2011). Legal and institutional challenges include among others agreements/contacts kickbacks and weak market links among others (Rueegg, 2009). Therefore, to increase the positive impacts of tourism on poor people, the participation of smallholder farmers in the tourism industry as well as the economic benefits of the farmers from tourism activities, linkages between tourism sector and agricultural enterprises has to be promoted (Ashley et al., 2006; Bengesi, 2018; Mshenga and Owuor, 2009). It is from this context this study was staged to examine factors influencing tourism - horticulture linkages and how it enhances income of smallholder farmers in Zanzibar.

\subsection{Methodology}

The study was conducted in Zanzibar. Zanzibar is an archipelago with small islands and islets in the Indian Ocean consists of two main islands, Unguja and Pemba, and several other smaller islets. This study covered all important tourism areas in Unguja Island namely Stone Town and Suburbs, North-East Coast and South-East Coast with respect to tourism domination, presence of on-going horticultural activities, presence of tourism establishments and availability of study data compared to Pemba Island. 
The Stone Town and Suburbs tourist zone forms the urban part of Zanzibar. It consists of several tourism attractions particularly the historic sites and the design of the old buildings, the Old Fort, Palace Museum, and the Anglican Cathedral with slave market. The dhow harbour and Forodhani Garden are also tourist attractions. The North-East Coast tourist zone stretched to Nungwi Strip, Matemwe, Pwani Mchangani, Kiwengwa, Pongwe, Chwaka and Uroa. It contains some of the popular beach destinations (e.g. Kendwa) for back packers and the young budget travellers.

The South-East Coast tourist zone starts from the Eastern Coast of Island from Michamvi to Kizimkazi and in the South it covers Bwejuu, Paje and Jambiani. This zone contains some of the popular beach destinations with several attractive tourist establishments.

The study adopted cross section research design to assess and analyse factors influencing tourism-horticulture linkages. The study involved smallholder farmers dealing with fresh fruits and vegetable production with less than 5 hectares and the hotels and restaurants were those served foreign tourists. To meet the study objective, purposive sampling was done for tourist hotels and systematic random sampling for smallholder farmers. Therefore, sample sizes of 85 out of 750 smallholder farmers and 31 out of 300 tourist hotels, respectively were used for this study.

The study used both primary and secondary data. The information was collected from smallholder farmers, tourist hotel respondents, key informants and reports from several institutions dealing with tourism and agriculture. Data processing and analysis were carried out using the Statistical Package for Social Science (SPSS) Version 16 computer software and logistic regression model was used to determine factors influencing tourism- horticulture linkages.

\subsection{Results and Discussion}

\subsection{Producer-Market Linkage}

Producer-market linkage in this study gives the framework to explain channels by which farmers sell their products after harvesting and how hotels source vegetables and fruits for their consumption. Figure 1 gives a picture on the extent to which sample farmers can benefit from existence of tourist hotels by supplying vegetables and fruits.

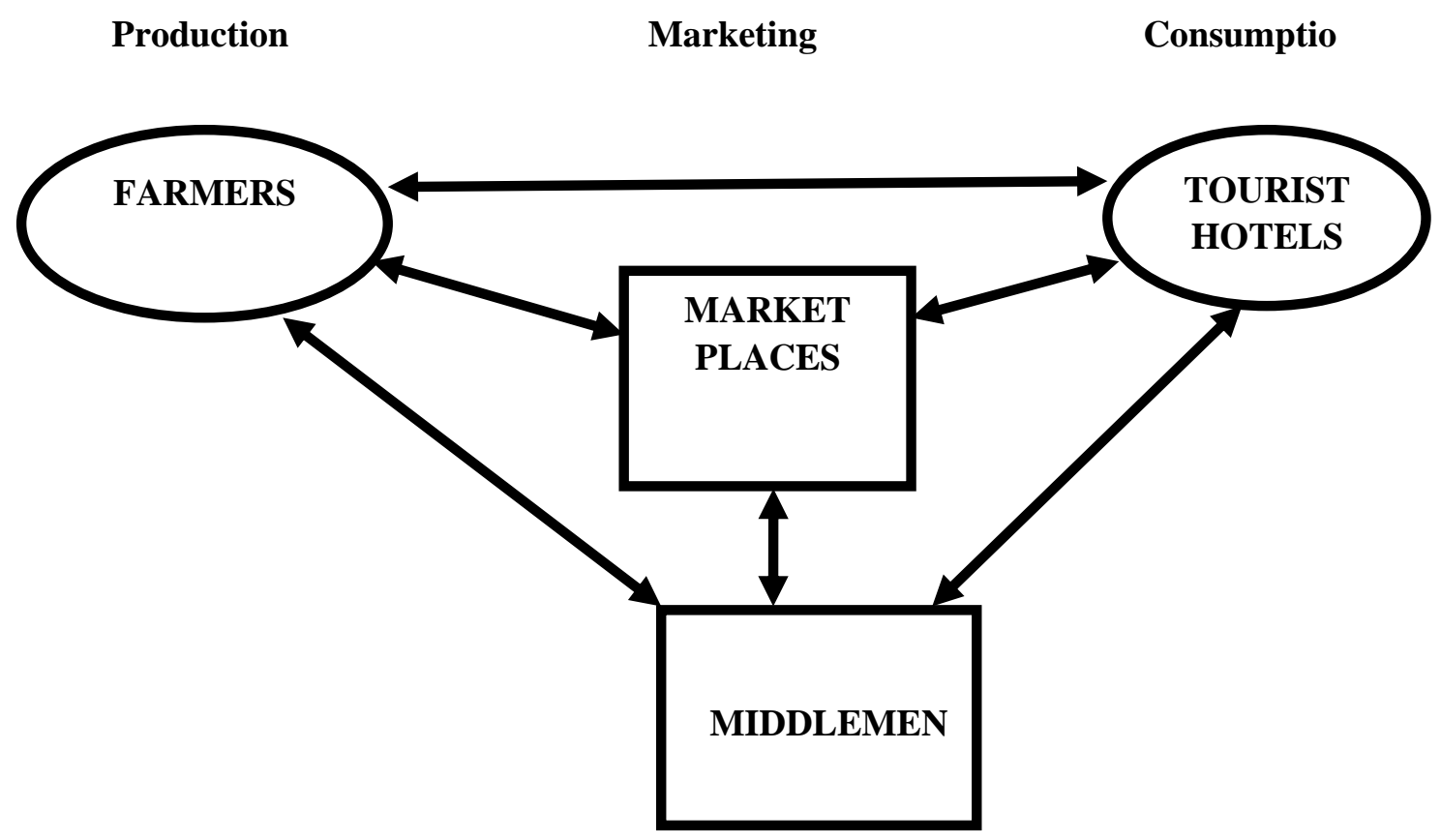

Figure 1: Producer-Market Linkage 
When farmers harvest vegetables and fruits for sale, they are likely to sell in three possible points, which are tourist hotels, market places or middlemen. Tourist hotels have also three sourcing points, which are farmers, market places, and middlemen. Middlemen can source vegetables and fruits from either farmers or market places or both farmers and market places and supply the products to tourist hotels. Despite existence of these market opportunities the smallholder farmers in Zanzibar have failed to take advantage of the emerging tourist market. Failure of farmers to take advantage of emerging opportunities in the tourist industry is partly due to inadequate enterprise mind-set among smallholder farmers to be able to predict the market dynamics and be able to plan beforehand. According to Bengesi and Le Roux (2014a) and Bengesi (2013) strategic entrepreneurial intervention is crucial to inculcate entrepreneurial mind-set among smallholder farmers to create innovative and creative thinking to cope with the changes taking place in the market environment.

\subsection{Factors Influencing Tourism Horticulture Linkage}

Examining factors influencing tourism-horticulture linkage the logistic regression was used test response variable on the predictor variables. Taking cognisance of the objective of the study, which was about analysing factors influencing tourism-horticulture linkage, it was crucial to analyse how hotel sourcing vegetables and fruits from producers are influenced by other hotel and farmers' characteristics.

Logistic regression model contained all predictors was statistically significant, indicating that the model was able to distinguish between the hotels which sourced and those which did not source from producers. Table 1 shows that four independent variables i.e. tourist zones, manager's nationality, quality of vegetables and fruits from farmers and supply of vegetables and fruits from farmer made a unique significant contributions to chances of tourist hotels sourcing vegetables and fruits from producers. The subsequent sections explain the contribution of these factors.

\subsubsection{Quality of Vegetables and Fruits from Farmer}

The strongest predictor of sourcing from producers was quality of vegetables and fruits from farmer, recorded an odds ratio of 37.98 (Table 1). This indicated that hotels were nearly 38 times more likely to source vegetables and fruits from producers who had good quality vegetables and fruits than those who had poor quality vegetables and fruits, controlling all other factors in the model. The findings imply that smallholder farmers can supply to tourist hotels provided their products are in good quality. Good quality products refer to size, shape and colour of the product as well as clean, well packed and undamaged products that ensure long shelf life. Meyer (2006) mentioned the quality of locally produced food to be often the key limitation for inter - sectoral linkages with tourism industry. Regarding high quality of products needed in tourist hotels, foreign managed hotels and those of a higher star-rating had a greater propensity to source from international suppliers rather than local producers (Bengesi et al., 2015). This altogether has connotation of quality products from international suppliers compared to local suppliers.

\subsubsection{Regular Supply of Vegetables and Fruits from Farmers}

Another strong predictor of sourcing from producers was supply from farmer, which recorded an odds ratio of 28.75 in Table 1 . This indicated that hotels were nearly 29 times more likely to source from producers who had regular supply of vegetables and fruits than those who had irregular supply of vegetables and fruits, controlling all other factors in the model. Regular supply refers to supply of vegetables and fruits according to required time and quantity (Le Roux \& Bengesi, 2014). The findings imply that hotels prefer to source vegetables and fruits using middlemen for regular supply after better informing about quality and volume requirements. This result confirms the literature in the sense that in most cases smallholder farmers are unreliable in terms of regularity of supply or fulfilling other contract agreements (Bengesi \& Abdalla, 2018; Rogerson, 2012). Hotels accept an opportunity of sourcing vegetables and fruits from producers only if they are assured of satisfactory regular supply. Therefore, farmers and local suppliers have to adopt regular supply mechanisms such as collecting vegetables and fruits from associated members and supply them to hotels. 
Table 1: Logistic Regression for Hotels Sourcing Vegetables and Fruits from Producers

\begin{tabular}{llllll}
\hline Variables & B & S.E. & Wald & $\boldsymbol{p}$-value & $\mathbf{E x p ( B )}$ \\
\hline Tourist zones & 2.631 & 1.016 & 6.706 & $0.010^{* *}$ & 13.888 \\
Manager Nationality & -1.529 & 0.703 & 4.728 & $0.030^{*}$ & 0.217 \\
Quality from farmer & 3.637 & 1.644 & 4.896 & $0.027^{*}$ & 37.979 \\
Supply from farmer & 3.359 & 1.663 & 4.078 & $0.043^{*}$ & 28.752 \\
Supply from middlemen & 0.175 & 1.294 & 0.018 & $0.893^{\text {ns }}$ & 1.191 \\
Constant & -5.381 & 2.734 & 3.874 & 0.049 & 0.005 \\
\hline
\end{tabular}

*and ** significant at $p<0.05$ and $p<0.01$, respectively

Dependent variable: Source from producer

ns $=$ statistically non-significant at 0.05 level of significance

\subsubsection{Hotel and Tourist Zones}

Tourist zones recorded an odds ratio of 13.89 as a predictor of hotel sourcing vegetables and fruits from producers (Table 1). Tourism zones indicated that hotels situated in North East Coast and South East Coast were 14 times more likely to source vegetables and fruits from producers than hotels from Stone Town and Suburban zone, given that all other factors in the model are constant. The findings imply hotels which are not in proximity to major wholesale markets more often prefer sourcing from local producers possibly due to high transport costs. The findings suggest that smallholder farmers residing close to tourist hotels in their respective zones have to organize themselves for quality vegetables and fruits production and fetch a market from these hotels.

\subsubsection{Nationality of Hotel Managers}

Nationality of hotel managers revealed the odds ratio of 0.22 to be less than 1 , indicating that when hotel managers were not Zanzibaris, hotels were 0.22 times less likely to source vegetables and fruits from producers, controlling other factors in the model. The findings imply that hotels managed by Zanzibaris and operated by local chef are more likely to source vegetables and fruits from local producers than foreign managed hotels. Meyer (2006) reported similar findings on the tendency of foreign owned or managed hotels and expatriate chefs to be reliant upon imports and having weak links to local producers.

The results of this study suggest that existence of the socio-economic relationship among local hotel managers and producers is necessary for smallholder farmers to take advantage of the emerging tourism market. Bengesi and Le Roux (2014b) argued that the networking capability in any social relationship is essential for smallholder farmers in overcoming entry barriers and providing market access for their vegetables and fruits supply to hotels. Rimal and Onyango (2011) also confirmed on the effect of hotel ownership and food purchases by indicating that independently and locally owned restaurants were more likely to buy locally produced fresh vegetables than those belonging to national or regional chains.

\subsection{Conclusion and Recommendations}

The study identified the structure of existing relationship between tourism industry and horticulture sub-sector in Zanzibar by mapping the linkages between tourist hotels and smallholder farmers of vegetables and fruits. Determining factors influencing tourism-horticulture linkage, tourist hotels were observed to consider several factors before accepting to source vegetables and fruits from local producers. However, the most prominent factors for the tourist hotels to source from local producers were quality of vegetables and fruits supplied locally, hotel tourist zones, nationality of hotel managers and regular supply of vegetables and fruits from farmers. Failure of farmers to take advantage of emerging opportunities in the tourist industry is partly due to inadequate enterprise mind-set among smallholder farmers.

Based on the findings, the paper recommends that strategic intervention is crucial to inculcate entrepreneurial mind-set among smallholder farmers to take advantage of emerging tourism market in Zanzibar. The smallholder farmers should emphasise on agribusiness practices to promote quality and supply of locally produced vegetables and fruits to be able to tap potential of tourists market in Zanzibar. The agribusiness practices in farming will also inculcate entrepreneurial mind set among smallholder farmers essential to come up with innovative ideas which will stimulate agricultural growth and ensure steady supply of vegetable and fruits in tourists' hotels. 
This paper also recommends further studies on horticultural products market channels to compare profits accrued in different supply chains and market segments. The exploration of these market segments and supply chains will assist smallholder farmers to identify the most profitable option for them to take advantage.

\section{References}

Ali, M., Farooq, U. and Shih, Y. (2002). Vegetable Research and Development in the ASEAN Region: A guideline for setting priorities. In: Kuo, C. G. (Ed.), Perspectives of ASEAN Cooperation in Vegetable Research and Development. AVRDC, Shanhua, Taiwan. 20-64pp.

Anderson, W. and Juma, S. (2011). Linkages at Tourism Destinations: Challenges in Zanzibar. Journal of Tourism Research 3(1): $27-41$.

Ashley, C., Goodwin, H., McNab, D., Scott, M. and Chaves, L. (2006). Making Tourism Count for the Local Economy in the Caribbean: Guidelines for good practice.

[www.propoortourism.org.uk/caribbean/brief3w.pdf] site visited on 02/05/2012.

Bengesi, K.M.K. (2018). Factors Hindering Use of Standard Weights and Measures along Irish Potato Supply Chain in Njombe Region, Tanzania. International Journal of Business and Management, 13(8):196-206

Bengesi, K. M. K. (2013). Strategic Entrepreneurial Response of Small and Medium Enterprises. PhD. University of Pretoria. Available: https://repository.up.ac.za/bitstream/handle/2263/24259/Complete.pdf?sequence=7. Accesses on 14 October 2017

Bengesi, K.M.K., \& Abdalla, J. O. (2018). Forces Driving Purchasing Behaviour of Tourists Hotels Along Tourist-Agricultural Supply Chain in Zanzibar. International Journal of Marketing Studies, 10(2):36-46.

Bengesi, K.M.K., Massawe, F.A. \& Rogers, A. (2015). Assessment of Coffee Marketing System in Kagera Region. Available from: https://www.mviwata.org/study-reports/ [Date accessed 25 January 2018].

Bengesi, K. M. K., \& Le Roux, I. (2014a). Strategic Entrepreneurial Response of Small and Medium Enterprises in Developing Economies. International Journal of Business and Management, 9(2):153-165. http://dx.doi.org/10.5539/ijbm.v9n2p153.

Bengesi, K. M. K., \& Le Roux, I. (2014b). The Influence of Dimensions of Networking Capability in Small and Medium Enterprise Performance. International Journal of Business and Social Science, 5(2):189-200.

Boyne, S., Williams, F. and Hall, D. (2001). Rural Tourism and Food Production: Opportunities for Sustainable Development, ROOTS 2001 Conference, RICS Foundation, http://www.rics.org/site/scripts/download_info.aspx? Site visited on 26/O6/2014.

Honeck, D. (2008). LDC Poverty Alleviation and the Doha Development Agenda: Is Tourism being neglected? World Trade Organization, 46pp.

Luvanga, N. and Shitundu, J. (2003). The Role of Tourism in Poverty Alleviation in Tanzania. Research report No. 4. On poverty alleviation. Mkuki na Nyota Publishers Limited, Dar es Salaam, Tanzania. 55pp.

Le Roux, I. \& Bengesi, K.M.K. (2014). Dimensions of Entrepreneurial Orientation and Small and Medium Enterprise Performance in Emerging Economies. Development Southern Africa, 31(4):606-624.

Meyer, D. (2006). Caribbean Tourism, Local Sourcing and Enterprise Development: Review of the literature. Working Paper No.18, Pro-Poor Tourism Partnership, London. 72pp.

Meyer, D. (2007). Pro-poor Tourism: From Leakages to Linkages: A Conceptual Framework for Creating Linkages between the Accommodation Sector and Poor Neighbouring Communities. Current Issues in Tourism 10: 558 - 583.

MFEA (2009). Growth Drivers and their Implications for Poverty Reduction. Ministry of Finance and Economic Affairs. Zanzibar. 81pp.

MFEA (2011). Ministry of Finance and Economic Affairs, Zanzibar. Zanzibar Economic Bulletin 4(1): 24 - 34.

Mshenga, P. M. (2010). Tourism and Agriculture Linkages: Determinants of Local Agricultural Products Purchase by Hotels at the Kenyan Coast, Research Application Summary Second REFORM Biennial Meeting 20-24 September 2010, Entebbe, Uganda. 1679-1682 pp.

Mshenga, P. M. and Owuor, G. (2009). Opportunities for Micro and Small Scale Business in The Tourism Sector: The Case of the Kenya Coast. KCA Journal of Business Management 2: $52-68$.

OCGS, (2013). Statistical Report on Socio-Economic Survey 2012. Office of Chief Government Statistician (OCGS), Zanzibar. 100pp.

RGZ (2004). Ministry of Tourism Trade and Investment. Zanzibar Tourism Policy Statement, Zanzibar. [www.zanzibartourism.net/docs/policystatement.pdf]. Site visited on 07/06/2014. 
RGZ (2009). Zanzibar Human Development Report. Towards pro poor growth. Revolutionary Government of Zanzibar (SMZ), Zanzibar. 150pp.

RGZ (2010). The Zanzibar Strategy for Growth and Reduction of Poverty (ZSGRP II): Revolutionary Government of Zanzibar, Zanzibar. 197pp.

Rimal, A. and Onyango, B. (2011). Purchasing Locally Produced Fresh Vegetables: National Franchise Vs. Locally Owned and Operated Restaurants.

[http://ageconsearch.umn.edu/bitstream/103464/2/AAEA_Manuscrpt_2011.pdf] site visited on 26/06/2014.

Rogerson, C. (2012). Strengthening Agricultural Tourism Linkages In The Developing World: Opportunities, Barriers And Current Initiatives. African Journal of Agricultural Research 7(4): 616 - 623.

Rueegg, M. (2009). The Impact of Tourism on Rural Poverty through Supply Chain Linkages to Local Food Producers in the Bolivian Altiplano. Dissertation for Award of MSc Degree at London School of Economics, Political Science, 49pp.

Subramanian, S., Varadarajan, S. and Asokan, M. (2000). Dynamics of Vegetable Production and Consumption in Asia. In: Ali, M. (Ed.), Asian Vegetable Research and Development Center, Shanhua, Taiwan. 476pp.

Timms, B. F. and Neill, S. (2011). Cracks in the Pavement: Conventional Constraints and Contemporary Solutions for Linking Agriculture and Tourism in the Caribbean. In: Torres R. and Momsen J. (Eds.), Tourism and Agriculture: New Geographies of Production and Rural Restructuring, Routledge, London. pp. 104-116.

Torres, R. and Momsen, J. (2011). Introduction. In: Torres, R. and Momsen, J. (Eds.), Tourism and Agriculture: New Geographies of Production and Rural Restructuring. Routledge, London. 9pp.

UNCTAD (2007). FDI in Tourism: The Development Dimension, Current Studies on FDI and Development No.4. United Nations. 168pp.

URT (2003). Indicative Tourism Master Plan for Zanzibar and Pemba, Dublin, Ireland. [www.zanzibartourism.net/docs/masterplan.pdf] site visited on 2/5/2014.

VSO (2015). Value Chain Analysis of the Fruit and Vegetable Market for Smallholder Farmers in Zanzibar. Volunteer Services Overseas, Dar Es Salaam. 38pp.

ZATI (2009). Zanzibar Agricultural Transformation Initiative for Sustainable Development, 2010-2020 for Agricultural Productivity, Food Security and Sustainable Livelihood. [http://www.kilimoznz.or.tz/images/Agrictransform.pdf.] site visited on 26/06/2014.

ZCT (2011). Tourist database. Accessed in Tanzania tourist board statistics. Zanzibar Commission for Tourism. [www.zanzibartourism.net/news.php] site visited on 27/05/2014. 